Ann. Biol. anim. Bioch. Biophys., 1979, 19 (1B), 173-180.

\title{
Importance of exogenous saturated fatty acids during brain development and myelination in mice
}

\author{
par J. M. BOURRE, Nicole GOZLAN-DEVILLIERRE, O. MORAND, Nicole BAUMANN \\ Laboratoire de Neurochimie, INSERM U 134 \\ Hôpital de la Solpêtrière, 75634 Paris Cedex 13, France.
}

Summary. The saturated fatty acid of exogenous origin of brain membranes is an important parameter in the synthesis of these membranes. After injection, labelled stearic acid was transported into the brain and incorporated into brain lipids. The labelled stearic acid taken up was partly metabolized in the brain either by elongation or by degradation and in situ resynthesis of fatty acids. The activity of oleic acid and mono-unsaturated chains was detectable. The labelled acids were incorporated into lipids or subcellular particles following characteristic kinetics, which showed a diminution by $24 \mathrm{hrs}$. When analyzing the evolution of each lipid, the phospholipids followed this pattern, but the cerebrosides and free fatty acids did not. The cerebrosides increased up to $50 \mathrm{hrs}$, while the free fatty acids remained stable, suggesting a physical binding between membranes and these acids. Myelin lipid radioactivity increased up to 3 days. Most of the activity was found in phospholipids; their fatty acids were labelled in saturated as well as in polyunsaturated homologues. However, sphingolipids, especially cerebrosides, also contained large amounts of radioactivity, mainly found in very long chain fatty acids such as lignoceric acid. The presence of unesterified fatty acids was observed. Unlike other lipids, these molecules were found in constant amounts, expressed in radioactivity per $\mathrm{mg}$ myelin lipid. The subcutaneously injected stearic acid was taken up by the brain through the blood-brain-barrier and incorporated into synaptosomal lipids as well as into other brain compartments. Phospholipids were potent acceptors. Moreover, a high level of radioactivity occurred in non-esterified fatty acids. A large amount of radioactivity was measured in isolated neurons and astrocytes. The bloodbrain relationship for stearic acid varied during development. Subcutaneously injected $\left({ }^{14} \mathrm{C}\right)$ stearic acid was taken up by brain with related changes from birth to maturity. Total lipid radioactivity reached a maximum at 18 days of age and decreased afterwards until adulthood. However, specific radioactivity presented a higher value at 1 day of age and declined from then on. The injected acid was taken up at any age and partly metabolized in the brain either by elongation or by degradation in situ and resynthesis of new fatty acids. It was also desaturated and the oleic acid formed was eventually elongated. The incorporation of labelled stearic acid into brain lipid varied with the age of the injected animal.

\section{Introduction.}

The brain does not utilize fatty acids to any extent for energy, but has the ability to synthesize most lipids. However, fatty acids necessary for membrane formation can be obtained endogenously or exogenously. Dietary studies with essential fatty acids have shown that transport from blood to brain is possible. Saturated fatty acids are synthesiz- 
ed in brain from endogenous or exogenous acetate; the enzymes are located in the soluble part of the cell, in mitochondria and in microsomes (Bourre et al., 1977a). Radioactive saturated fatty acids are taken up by brain either when fed (Dhopeshwarkar and Mead, 1969) or when injected (Bourre et al., 1974), but there is no evidence indicating whether saturated fatty acids, when incorporated into membranes, are mainly biosynthesized in sifu or whether they come from blood. Obviously essential fatty acids are predominantly taken up directly without prior degradation to acetate, and are partly elongated. This work was undertaken to study the fate of a saturated fatty acid (stearic acid) in train after subcutaneous injection to know whether it was incorporated into lipids of subcellular particles as such or after being metabolized. The time of myelination was chosen for this study, as it is an active period of membrane formation. Stearic acid was used as it is the primer for very long-chain fatty acids in brain (Bourre et al., 1970).

\section{Material and methods.}

Subcutaneous injection of labelled $\left({ }^{14} \mathrm{C}\right)$ stearic acid was performed as previously described (Gozlan-Devillierre ef al., 1976). Animals were injected in relation to the body weight $(10 \mu \mathrm{Ci} / \mathrm{g})$ and killed by exsanguination. The lipids were analysed by thinlayer chromatographies (Gozlan-Devillierre et al., 1978a, b) and blood or brain fatty acids were quantified by gas-liquid chromatography with automatic eluate counting.

Density gradient was used to prepare myelin (Norton and Poduslo, 1973) and synaptosomes (Bourre ef al., 1977b). Neurons and astrocytes were obtained by trypsition, screening and density gradient (Norton and Poduslo, 1970).

\section{Results.}

1. Uptake of labelled stearic acid by whole brain total lipids (Gozlan-Devillierre et al., 1976).

We measured the uptake of radioactivity by total brain lipids and by the main classes of lipids of 18-day old mice after a subcutaneous injection of $\left(1-1^{14} \mathrm{C}\right)$ stearate. The percentage of radioactivity found in cerebrosides always increased in contrast to the free fatty acids. Little activity was found in sphingomyelin ( 1 to 4 p. 100 according to the time point), sulfatides and cholesterol. But activity in both sphingomyelin and sulfatides increased. The activity in total lipid extract (radioactivity in cpm per mg lipid extract) augmented up to $20 \mathrm{hrs}$. and then decreased until $24 \mathrm{hrs}$. to rise again and reach a plateau at 50 hrs. (no activity was measured at zero time). Radioactivity was present in all major components indicating active incorporation into brain constituents. Most of the radioactivity in the lipids was found in choline phosphoglycerides, inositol phosphoglycerides and serine phosphoglycerides. At 20 hrs. after injection, the main phospholipids (choline-phosphoglycerides, inositol-phosphoglycerides, serine-phosphoglycerides and ethanolamine-phosphoglycerides) accounted for about 70 p. 100 of the total radioactivity. When PI, PC and PS were separated individually, a large part of the percentage of total phospholipid activity was present in PC, but the pattern of evolution (as a function of injection time) was the same in all phospholipids. While the 
activity of total lipids and phospholipids had decreased at $24 \mathrm{hrs}$., that of cerebrosides diminished much less and continued to augment. Sulfatide activity was less than 5 p. 100 at each time point, but it also increased. The activity of free fatty acids remained remarkably constant during that time.

The acyl groups of the lipid extract were converted to fatty acid methyl esters for gas liquid chromatographic analysis. The lipid extract contained a high amount of labelled stearic acid $(94.3$ p. 100$) 10 \mathrm{~min}$. after injection of $\left(\mathrm{l}^{14} \mathrm{C}\right)$ stearic acid. 5.2 p. 100 radioactive palmitic acid was already present at that time. Labelled stearic acid decreased gradually and, conversely, labelled palmitic acid increased until $20 \mathrm{hrs}$. with a maximum at $24 \mathrm{hrs}$. The level of labelled arachidic was low but not negligible. Longer labelled chaines of behenic and lignoceric acids were detectable. Except for trace amounts of oleic acid (less than 3 p. 100 of total radioactivity), unsaturated fatty acids were not found. On the other hand, in blood we observed only labelled stearic acid and no longer or shorter chains. This indicates that the administered stearic acid was predominately taken up directly without prior degradation to acelate. The total radioactivity was determined at each time point in blood and brain lipids. For instance, $1 \mathrm{hr}$. after injection of $70 \times 10^{6} \mathrm{cpm}$, the blood still contained $60.890 \mathrm{cpm}$, and the whole brain subcellular particles $9.780 \mathrm{cpm}$. Twenty hours after the same injection, $43.560 \mathrm{cpm}$ were found in the blood and $19.670 \mathrm{cpm}$ in brain subcellular particles.

Chemical decarboxylation showed most of the radioactivity to be in the carboxylend ( 85 p. 100 and 65 p. 100 at $1 \mathrm{hr}$. and $18 \mathrm{hrs}$. after injection, respectively). Thus, the injected acid was actually transported through the blood-brain-barrier.

2. Distribution of radioactivity in myelin lipids following injection of labelled stearate (Gozlan-Devillierre et al., 1978a).

$\left(1-{ }^{14} \mathrm{C}\right)$ stearic acid was taken up by myelin lipids of 18-day old mice after injection. The percentage found in sphingolipids increased with the highest radioactivity in cerebrosides. The radioactivity in phospholipids also increased, in contrast to that in free fatty acids. Little activity was found in the cholesterol fraction. The upper Folch phase, including mainly gangliosides, contained 10 p. 100 of total brain radioactivity; 0.03 p. 100 of the injected acid was recovered in total brain lipids, and 0.005 p. 100 in myelin 20 hrs. after injection.

The activity in the lipid extract (radioactivity in cpm) increased drastically up to $10 \mathrm{hrs}$., then levelled off slowly although still positive $48 \mathrm{hrs}$. after injection. The radioactivity of each individual lipid fraction continuously increased, but the activity of free fatty acids remained constant with time. These free fatty acids were very tightly bound to myelin ; incubation of a suspension of $0.4 \mathrm{mg} / \mathrm{ml}$ myelin in the presence of $1 \mathrm{mg} / \mathrm{ml}$ delipidated albumin did not extract any activity. Moreover, when pure myelin, from animals not treated with radioactive acids, was incubated in the presence of $\left({ }^{14} \mathrm{C}\right)$ stearic acid, the uptake was very low. Thus, fatty acids were taken up by myelin membrane in vivo through active metabolism, nol simply by physical non-specific binding, and those embedded in the myelin sheath were not available for albumin extraction. The myelin free fatty acids must have a high specific radioactivity, as they were found in minute amounts in brain.

The radioactive fatty acid profile was determined in each lipid isolated $20 \mathrm{hrs}$ after injection. It should be noted that cerebrosides contained a high amount of radio- 
active very long chain fatty acids, especially at the level of lignoceric acid. The smallest amount of radioactivity was found in stearic acid. Non-esterified fatty acid fractions contained mainly stearic acid and palmitic acids; the same acids were found in phospholipids, but the radioactivity determined in $\mathrm{C}_{20}$-polyunsaturated fatty acid was quite high.

Two days after injection, sphingolipids still contained labelled very long chain fatty acids. But cerebrosides included nearly the same amount of lignoceric acid at 2 days and at 20. This is also true of sulphatides, which consisted of large amounts of radioactive lignoceric acid (This is to be expected as sulphatides are synthesized by sulphation of cerebrosides). The activity found in palmitic acid in all lipids, when labelled stearic acid, was injected was due to degradation to radioactive acetate and the subsequent biosynthesis of medium chain fatty acids through a de novo procedure. This radioactive acetate is probably used in elongation systems and also for synthesis of cholesterol, thus explaining the radioactivity found in this compound. In phospholipids, the radioactivity in oleic acid was very low. The radioactivity in very long chain monounsaturated fatty acids in sphingolipids was hardly detected; this is unexpected, as brain microsomes are able to desaturate stearate to oleate, this latter molecule being further elongated to longer mono-unsaturated chains. However, activity was detected in the poly-unsaturated fatty acids involved in phospholipids, and thus stearic acid when injected was desaturated and elongated.

3. In vivo incorporation of exogenous $\left(\mathrm{I}^{14} \mathrm{C}\right)$ stearic acid in synaptosomes (Bourre et al., 1977b).

All major lipids included 60 p. 100 radioactivity, indicating active incorporation into synaptosomal lipids. Among the phospholipids, the choline phosphatides presented the highest radioactiviy, followed by ethanolamine phosphatides and serine phosphatides. Of the total radioactivity, 0,8 p. 100 was found in cholesterol esters, cerebrosides, ceramides, monogalactosyl diglycerides and some unidentified spots. The very high radioactivity detected in unesterified fatty acids must be mentioned; about 30 p. 100 of the total radioactivity in the lower phase was found in these molecules. 29.8 p. 100 of the radioactivity of the upper Folch wash was found in non-esterified fatty acids, 48.5 p. 100 being in gangliosides and the rest staying at the origin, possibly covalently bound to proteolipids.

Fatty acid analysis showed most of the radioactivity to be in stearic acid (75 p. 100), and some in palmitic acid, oleic acid and poly-insaturated fatty acids with 20 and 22 carbon atoms.

4. Presence of the subcutaneously injected $\left(1-{ }^{14} \mathrm{C}\right)$ acid in neuronal and glial cells (Morand et al., unpublished).

The presence of labelled stearic acid was studied in isolated neurons and astroglial cells. When animals were killed at various times after injection, the amount of radioactivity increased in both cell types, and astrocytes showed a higher specific activity when compared to neurons (expressed in $\mathrm{cpm}$ per $\mathrm{mg}$ proteins, the values are, respectively, 2.200 and 800 at $20 \mathrm{hrs}$.) The yield of cells recovered from the brain sample is about 20 p. 100. 
5. Incorporation of stearic acid into lipids of the developing brain (Gozlan-Devillierre et al., 1978b ; Bourre ef al., 1978).

The activity in total lipid extract (radioactivity in cpm per brain) increased up to 18 days of age and then decreased until adulthood. Specific activity (in cpm $\mathrm{mg}$ of lipid extract) was maximum at 1 day of age and then decreased. It is interesting to note that maximum total activity corresponded to maximum myelination (myelination in mice reaches a peak at 18 days). However, the activity related to brain lipid content was maximum during the first day of postnatal life, possibly in connection with glial cell multiplication. Thus, during brain maturation, the uptake of stearic acid varied. Radioactivity was present in all major components, indicating active incorporation into brain constituents. Most of the radioactivity in lipids was found in choline phosphoglycerides, but the evolution was not the same for all phospholipids. Choline phosphoglycerides and inositol phosphoglycerides increased until 21 days of age and then decreased. The percentages of radioactivity found in cerebrosides, sulfatides and sphingomyelin showed a maximum at 18 days of age. The percentage of free fatty acids was nearly constant at all ages. Some activity was also found in cholesterol at all the ages studied, suggesting that stearic acid was degraded to radioactive acetate which was, in turn, used for cholesterol synthesis.

The evolution of uptake of radioactivity in the major classes of lipids after injection of $\left(1-{ }^{14} \mathrm{C}\right)$ stearate shows that $\mathrm{PC}$ and cerebrosides present maximum activity at 15 days of age, PE at 18 days of age and PS at 21 days of age. At all ages studied, injected stearic acid is partly degraded to radioactive acetate; subsequent de novo biosynthesis or elongation of endogenous short chains within brain explains the presence of $C_{14}$ and $C_{16}$ acids. The level of arachidic acid is low but not negligible. This indicates that stearic acid is partly elongated. Oleate is also radioactive.

\section{Discussion.}

1. Transport of stearic acid across the blood-brain-barrier is studied by subcutaneous injection, as feeding also involves metabolism in the digestive tract, and direct injection into brain excludes the blood-brain-barrier. But the liver may elongate some injected fatty acids, these newly biosynthesized fatty acids being released into blood and then taken up by brain. Our technique excludes any contamination by blood for we only isolate subcellular particles which were washed to discard any contamination from cytosol. This work demonstrates that stearic acid as such is transported from blood to brain. Gas-liquid radio chromatography of blood fatty acids shows only trace amounts of fatty acids other than stearic acid. Injected fatty acid penetrates in brain infact and is further metabolized. In brain, some activity is found in fatty acids with 20 , 22 and 24 carbon atoms, indicating that stearic acid is partly elongated. The activity found in palmitic acid when stearic acid is injected is probably due to degradation to radioactive acetate and subsequent biosynthesis or elongation of endogenous short chains within brain. Moreover, this radioactive acetate is also used for synthesis of cholesterol. Further results have been presented with fed essential fatty acids (Dhopeshwarkar ef al., 1969, 1971a, b). 
2. Blood fatty acids are an important parameter in myelin membrane synthesis, as exogenous stearic acid is needed; after subcutaneous injection to 18-day old mice this labelled stearic acid is transported into brain myelin and incorporated into its lipids. However, the acid is partly metabolized in the brain by elongation (providing very long chain fatty acids, mainly lignoceric acid) or by degradation to acetate units (utilized for synthesis of medium chain fatty acids as palmitic acid and cholesterol). These metabolites are further incorporated into myelin lipids.

Myelin lipid radioactivity increases up to 3 days; high activity is found in phospholipids, and their fatty acids are labelled in saturated as well as in poly-unsaturated homologues. But sphingolipids, and especially cerebrosides, also contain large amounts of radioactivity (mainly found in very long chain fatty acids, principally in lignoceric acid). The presence of unesterified fatty acids must be mentioned. These molecules, unlike other lipids, are found in constant amounts (expressed in radioactivity per mg myelin lipid).

During nutritional deprivation, myelin synthesis diminishes (Wiggins et al., 1976). If radioactive essential fatty acids are taken up by brain, these poly-unsaturated fatty acids are poorly incorporated into myelin lipids, as this membrane contains large amounts of sphingolipids including saturated and mono-unsaturated fatty acids. This work demonstrates that a saturated fatty acid is taken up by brain and further incorporated into myelin lipids. It is not known whether it penetrates into brain in the free form, as a complex lipid or in still another form. This acid is either (i) directly incorporated into myelin, (ii) elongated in brain (providing arachidic and behenic acids), or (iii) metabolized to acetcte units needed for the synthesis of medium chain fatty acids, as palmitic acid, or for the elaboration of cholesterol. These metabolic products are partly incorporated into myelin lipids.

3. Subcutaneously injected acid is taken up by the brain through the blood-brainbarrier and incorporated into synaptosomal lipids as well as into other brain compartments. Phospholipids are potent acceptors (choline phosphatides, ethanolamine phosphatides, serine phosphatides). Moreover, a high level of radioactivity is found in non-esterified fatty acids. It is not known if these acids are derived from exogenous stearic acid by metabolism in synaptosomes, or if they are metabolized in another compartment e. g. neuronal pericaryon, and fixed thereafter in nerve endings.

The non-esterified fatty acid content of synaptosomes is higher than that of other membranes ( 26 p. 100 in myelin, 28 p. 100 in total membranes). It is still not known whether fatty acids in synaptosomes derive from axonal flow or originate locally by non-specific adsorption or active uptake.

Non-esterified fatty acids account for a high amount of the total radioactivity (about 36 p. 100). This observation may be correlated with synaptic transmission since these acids have been found in cerebral cortex in association with proteolipids (including cholinergic receptors), and the neurotransmitter modulated release of unesterified fatty acids may be part of the mechanism for controlling membrane permeability (Lunt and James, 1976).

4. Neurons and astrocytes, when isolated by trypsin digestion, screening and density gradient, contain some radioactivity ; further studies are in progress now to determine the site of labelling and its time course. 
5. Stearic acid is transported from blood into brain at varying rates during myelinogenesis. Total radioactivity (cpm/total brain lipids, i. e. mole fatty acids/total brain lipids) increases parallel to myelination and decreases thereafter. As stearic acid contains most of the radioactivity in brain and as no other labelled molecule is found in blood, the role of an exogenous saturated fatty acid on brain lipid biosynthesis is clearly demonstrated, and the results indicate a variation in the blood-brain relationship during development. However, when stearic acid incorporation is expressed in relation to the amount of brain lipids, there is a decrease as a function of age (expressed in specific radioactivity : $\mathrm{cpm} / \mathrm{mg}$ lipids, i. e. mole fatty acids per $\mathrm{mg}$ lipids). Although this curve takes into account the amount of lipids deposited before injection, it may indicate the importance of exogenous fatty acids at the period of glial cell multiplication which occurs in the first week after birth. Thus exogenous stearic acid seems to be relatively more important during cell multiplication than during myelination. These results are not related to an increased catabolism in situ as $\beta$-oxydation is very low in the brain.

Indeed, the notion of essential fatty acids is familiar and, as established in the rat, poly-unsaturated fatty acids from milk may provide a source for the developing brain. The nutritional saturated fatty acid requirement during development demonstrated in our experiments has not been previously described, and it is fundamental in determining the origin of other brain fatty acids during development. It is also important to determine if feeding an abnormal diet can alter the fatty acid composition of the brain, thus modifying the structure and function of that organ.

As far as we know, the critical period for human babies, when the brain is more sensitive or vulnerable, begins with the second half of foetal life and ends at about 18 months after birth. During this growth spurt (Dobbing, 1972), brain vulnerability is critical and the fatty acid nutrition of the pregnant mother, and later of the newborn, contributes to normal brain development.

As fatty acid catabolism in the brain is very restricted, if a long chain enters, it will be likely to stay, and if complex lipids are degraded by physiological turn-over, the fatty acid moiety is reutilized for synthesis of new complex molecules. Thus, introduction of non-physiological fatty acids, such as branched chain or trans isomers, may have a long-term effect.

4 e Réunion du groupe Développement I.N.R.A. Montpellier, 17-18 moi 1978.

Résumé. La nutrition intervient dans la composition en acides gras saturés des membranes cérébrales. Après injection sous-cutanée, l'acide stéarique radio-actif est transporté dans le cerveau où il est incorporé dans les lipides cérébraux, sans avoir été au préalable dégradé en unités acétates permettant la resynthèse des acides gras. La contamination de la préparation « membranaire » par le sang est exclue. L'acide stéarique capté est en partie métabolisé par le cerveau, soit par allongement, soit par dégradation en unités acétate ef resynthèse in sifu d'acides gras. L'acide oléique et les acides mono-insaturés sont difficilement détectables. Les acides gras radioactifs sont incorporés dans les lipides « membranaires » selon une évolution temporelle qui montre une diminution à la $24 \mathrm{e}$ heure. L'analyse de chaque lipide montre que cette évolution est suivie par les phospholipides mais pas par les cérébrosides ou les acides gras libres : les premiers augmentent régulièrement jusqu'à $50 \mathrm{~h}$ au moins, les seconds sont stables (suggérant une liaison physique entre les membranes et les acides gras libres non estérifiés). La radioactivité des lipides myéliniques est croissante jusqu'à 3 jours, principalement dans les phospholipides. Les acides gras saturés sont 
marqués, mais aussi leurs homologues insaturés. Les sphingolipides, en particulier les cérébrosides, contiennent aussi de la radioactivité, principalement détectée sur les très longues chaînes telles que l'acide lignocérique. Les acides gras non estérifiés sont aussi marqués. Les lipides des synaptosomes, essentiellement les phospholipides, captent aussi l'acide stéarique exogène; les acides gras non estérifiés sont très importants. Après isolement des cellules gliales (astrocytes) et des neurones, l'analyse montre qu'ils contiennent aussi l'acide stéarique injecté. La relation «sang-cerveau » varie en fonction de l'âge de l'animal. Elle est quantativement maximale au moment de la myélinisation. Toutefois l'analyse des activités spécifiques montre que cette relation est capitale au moment de la multiplication cellulaire. De plus, l'utilisation de l'acide stéarique exogène pour élaborer les lipides cérébraux est différente selon l'âge et le type de lipide considéré.

\section{References}

BOURRE J. M., BOUCHAUD C., BAUMANN N., 1974. Evolution of brain lipids and fatty acids as a function of age. Relation with blood-brain-barrier. Arterial Wall, 427, 1-7.

BOURRE J. M., POLLET S., DUBOIS G., BAUMANN N., 1970. Biosynthèse des acides gras à longue chaîne dans les microsomes de cerveau de souris. C. R. Acad. Sci. Paris. Sér. D, 271, 1221-1223.

BOURRE J. M., POLLET S., PATURNEAU-JOUAS M., BAUMANN N., 1977a. Saturated and monounsaturated fatty acid biosynthesis in brain : relation to development in normal and dysmyelinating mice, 103-107. In BAZAN F., BRENNER R., GIUSTO N., Function and biosynthesis of lipids. Plenum Press, New York.

BOURRE J. M., GOZLAN-DEVILLIERRE N., POLLET S., MAURIN Y., BAUMANN N., 1977b. In vivo incorporation of exogenous stearic acid in synaptosomes : high occurrence of non-esterified fatty acids. Neurosci. Lett., 4, 309-315.

BOURRE J. M., GOZLAN-DEVILLIERRE N., DAUDU O., BAUMANN N., 1978. Is there a blood-brain relationship for saturated fatty acids during development. Biol. Neonate (in press).

DHOPESHWARKAR G., MEAD J. F., 1969. Incorporation of $\left(1-{ }^{14} \mathrm{C}\right)$ palmitic acid into the adult rat brain. Biochim. biophys. Acta, 187, 461-467.

DHOPESHWARKAR G., SUBRAMANIAN G., MEAD J., 1971a. Fatty acid uptake by the brain. Incorporation of $\left(1-{ }^{14} \mathrm{C}\right)$ linolenic acid into adult rat brain. Biochim. biophys. Acta, 239, 162-167.

DHOPESHWARKAR G., SUBRAMANIAN G., MEAD J., 1971b. Fatty acid uptake by the brain. Incorporation of $\left(\mid-{ }^{14} \mathrm{C}\right)$ linoleic acid into the adult rat brain. Biochim. biophys. Acta, 231, 8-14.

DOBBING J., 1972. Lipid malnutrition and the developing brain. Ciba Found. London, Pp. 929.

GOZLAN-DEVILLIERRE N., BAUMANN N. A., BOURRE J. M., 1976. Mouse brain uptake and metabolism of stearic acid. Biochimie, 58, 1129-1133.

GOZLAN-DEVILLIERRE N., BAUMANN N., BOURRE J. M., 1978a. Distribution of radioactivity in myelin lipids following subcutaneous injection of $\left({ }^{14} \mathrm{C}\right)$ stearate. Biochim. biophys. Acta, 528, 490-496.

GOZLAN-DEVILLIERRE N., BAUMANN N., BOURRE J. M., 1978b. Incorporation of stearic acid into brain lipids in the developing brain : blood-brain relationship during development. Dev. Neurosci. (submitted).

LUNT G., JAMES J., 1976. Unesterified fatty acids in rat cerebral cortex : their association with proteolipids. J. Neurochem., 26, 325-329.

NORTON W., PODUSLO S., 1970. Neuronal soma and whole neuroglia of rat brain : a new isolation technique. Science, 167, 1144-1145.

NORTON W., PODUSLO S., 1973. Myelination in rat brain : method of myelin isolation. J. Neurochem., 21, 749-757.

WIGGINS R., MOLLET S., BENJAMINS J., KRIGNEN M., MORELL P., 1976. Myelin synthesis during post-natal nutritional deprivation and subsequent rehabilitation. Brain Res., 107, 257-273. 